\title{
A novel Geobacteraceae-specific outer membrane protein J (OmpJ) is essential for electron transport to Fe (III) and Mn (IV) oxides in Geobacter sulfurreducens Eman Afkar ${ }^{1}$, Gemma Reguera*1, Marianne Schiffer ${ }^{2}$ and Derek R Lovley ${ }^{1}$
}

Address: ${ }^{1}$ Department of Microbiology, University of Massachusetts, Amherst, Massachusetts 01003, USA and ${ }^{2}$ Biosciences Division, Argonne National Laboratory, Argonne, Illinois 60439, USA

Email: Eman Afkar - eman_afkar@yahoo.com; Gemma Reguera* - greguera@microbio.umass.edu; Marianne Schiffer - mschiffer@anl.gov; Derek R Lovley - dlovley@microbio.umass.edu

* Corresponding author

Published: 06 July 2005

BMC Microbiology 2005, 5:4| doi:|0.|186/|47|-2|80-5-4|
Received: 28 January 2005

Accepted: 06 July 2005

This article is available from: http://www.biomedcentral.com/I47I-2/80/5/4I

(C) 2005 Afkar et al; licensee BioMed Central Ltd.

This is an Open Access article distributed under the terms of the Creative Commons Attribution License (http://creativecommons.org/licenses/by/2.0), which permits unrestricted use, distribution, and reproduction in any medium, provided the original work is properly cited.

\begin{abstract}
Background: Metal reduction is thought to take place at or near the bacterial outer membrane and, thus, outer membrane proteins in the model dissimilatory metal-reducing organism Geobacter sulfurreducens are of interest to understand the mechanisms of $\mathrm{Fe}$ (III) reduction in the Geobacter species that are the predominant $\mathrm{Fe}(\mathrm{III})$ reducers in many environments. Previous studies have implicated periplasmic and outer membrane cytochromes in electron transfer to metals. Here we show that the most abundant outer membrane protein of $G$. sulfurreducens, OmpJ, is not a cytochrome yet it is required for metal respiration.

Results: When outer membrane proteins of $G$. sulfurreducens were separated via SDS-PAGE, one protein, designated OmpJ (outer membrane protein J), was particularly abundant. The encoding gene, which was identified from mass spectrometry analysis of peptide fragments, is present in other Geobacteraceae, but not in organisms outside this family. The predicted localization and structure of the OmpJ protein suggested that it was a porin. Deletion of the ompJ gene in G. sulfurreducens produced a strain that grew as well as the wild-type strain with fumarate as the electron acceptor but could not grow with metals, such as soluble or insoluble Fe (III) and insoluble Mn (IV) oxide, as the electron acceptor. The heme c content in the mutant strain was ca. $50 \%$ of the wild-type and there was a widespread loss of multiple cytochromes from soluble and membrane fractions. Transmission electron microscopy analyses of mutant cells revealed an unusually enlarged periplasm, which is likely to trigger extracytoplasmic stress response mechanisms leading to the degradation of periplasmic and/or outer membrane proteins, such as cytochromes, required for metal reduction. Thus, the loss of the capacity for extracellular electron transport in the mutant could be due to the missing c-type cytochromes, or some more direct, but as yet unknown, role of OmpJ in metal reduction.

Conclusion: $\mathrm{OmpJ}$ is a putative porin found in the outer membrane of the model metal reducer $G$. sulfurreducens that is required for respiration of extracellular electron acceptors such as soluble and insoluble metals. The effect of OmpJ in extracellular electron transfer is indirect, as $\mathrm{OmpJ}$ is required to keep the integrity of the periplasmic space necessary for proper folding and functioning of periplasmic and outer membrane electron transport components. The exclusive presence of ompJ in members of the Geobacteraceae family as well as its role in metal reduction suggest that the ompJ sequence may be useful in tracking the growth or activity of Geobacteraceae in sedimentary environments.
\end{abstract}




\section{Background}

Fe (III) oxide is the most abundant metal electron acceptor in most soils and sediments and its microbial reduction greatly contributes to the degradation of organic matter in many sedimentary environments as well as to the degradation of organic contaminants in polluted groundwater $[1,2]$. Fe (III) also is the primary electron acceptor supporting the growth of dissimilatory metalreducing microorganisms when metal reduction is stimulated by adding a suitable electron donor to promote the in situ bioremediation of soluble metal contaminants [3] such as uranium [4] and vanadium [5]. Thus, understanding the mechanisms of electron transfer to insoluble $\mathrm{Fe}$ (III) oxides could greatly aid in the study of dissimilatory metal reduction in various sedimentary environments.

Despite the wide phylogenetic diversity of microorganisms capable of dissimilatory metal-reduction [1], molecular analyses of moderate temperature sedimentary environments in which Fe (III) reduction is important have routinely found that microorganisms in the Geobacteraceae are prevalent whereas other well-studied $\mathrm{Fe}$ (III)-reducing microorganisms, such as Shewanella species, are not detected [1]. This has been attributed, at least in part, to different mechanisms for Fe (III) reduction in these organisms. Geobacter species need to directly contact $\mathrm{Fe}$ (III) oxides in order to reduce them [6], have a highly specialized strategy for searching for Fe (III) oxides [7], and use pili as conductive nanowires to transfer electrons to the insoluble electron acceptor [8]. In contrast, Shewanella $[9,10]$ and Geothrix species [11] produce soluble electron shuttles and $\mathrm{Fe}(\mathrm{III})$ chelators which alleviate the need for direct contact with $\mathrm{Fe}$ (III) oxides.

Because of the insoluble nature of $\mathrm{Fe}(\mathrm{III})$ and $\mathrm{Mn}(\mathrm{VI})$ oxides, metal reduction in dissimilatory metal-reducing organisms is thought to occur at or near the outer membrane. Most studies on the mechanisms for Fe (III) reduction in Geobacter species have focused on the role of $c$-type cytochromes [12-14]. Over 110 putative c-type cytochrome genes have been identified in the G. sulfurreducens genome [15]. Many of these cytochrome genes are more highly expressed during growth on Fe (III) than with fumarate as the electron acceptor and deletion of some of these cytochrome genes greatly reduces the capacity for Fe (III) reduction $[13,14]$. However, the importance of $c$-type cytochromes in the final electron transfer to Fe (III) has been questioned because Pelobacter species, which are phylogenetically intertwined with Geobacter and Desulfuromonas species in the Geobacteraceae [16], can reduce $\mathrm{Fe}$ (III), yet do not appear to contain $c$-type cytochromes [17]. If, as expected, reduction of $\mathrm{Fe}(\mathrm{III})$ takes place at, or near, the outer membrane surface, then there may be outer membrane proteins other than $c$-type cytochromes, which have a role in electron transfer to Fe(III). In support of this, Geobacter's pili have recently been found to play a key role in electron transfer to insoluble metals by acting as microbial nanowires that extend the electron transfer capabilities of the bacterium beyond the cell surface [8].

Geobacter sulfurreducens has been routinely used as a model organism for investigations into Fe (III) reduction in Geobacteraceae because its complete genome sequence [15] and a genetic system [18] are available. Here we report that the most abundant protein in the outer membrane of G. sulfurreducens is not a cytochrome, yet this protein is required for $\mathrm{Fe}$ (III) reduction.

\section{Results \\ Identification and characterization of OmpJ}

One protein, designated outer membrane protein J (OmpJ), was much more abundant than any other protein in the outer membrane fraction of cells grown with fumarate as the sole electron acceptor (Fig. 1A). This protein also was present in cultures grown with other electron acceptors such as $\mathrm{Fe}(\mathrm{III})$ citrate, $\mathrm{Fe}(\mathrm{III})$ oxides and and $\mathrm{Mn}(\mathrm{IV})$ oxides (data not shown). MALDI-TOF mass spectrometry analyses identified eight peptides (MGDATVALGFAR, VDFGGWAANATAK, LITHFEIDSTWGK, FDPVTIDGFLLYQR, NVYLDENIPSTPLNVK, AFAIANVGFVAADKDNTTYCNAR, ALVYNVQNVIGGFVGYNANITSK, VFDNLTASVQGAYVILGDYFKDTAGTAANPEDPR) that uniquely corresponded to the protein encoded by ORF GSU3304 (gi-39998393), annotated as a putative LamB porin family protein in the genome of G. sulfurreducens. OmpJ had a predicted average molecular mass of $48.9 \mathrm{kDa}$, in accordance with its mobility in denaturing gels (Fig. 1A), and a theoretical pI of 6.25 compared with a pI of 6.7 determined by isoelectric focusing gel electrophoresis. The PSORT algorithm predicted OmpJ to be localized in the outer membrane, consistent with its presence in outer-membrane preparations (Fig. 1A).

Several secondary structure prediction methods predicted that OmpJ consists mainly of extended beta-chain fragments. Six of the first 20 predictions by 3D-PSSM [19], which uses a threading algorithm to predict the fold of a protein most homologous to structures deposited in the Protein Data Bank, suggest that OmpJ is a porin. The other predicted folds were for soluble proteins, which have large numbers of beta segments and thus appear to be inappropriate for a membrane-bound protein.

Several pieces of biochemical evidence also indicate that OmpJ may function as a porin. First, its localization in the outer membrane. OmpJ was associated to the outer membrane fraction of G. sulfurreducens and was isolated in a highly purified form after removal of the cytoplasmic membrane (Fig. 1A). Also, the apparent molecular weight of OmpJ in the absence of heating $(118 \mathrm{kDa})$ was roughly 

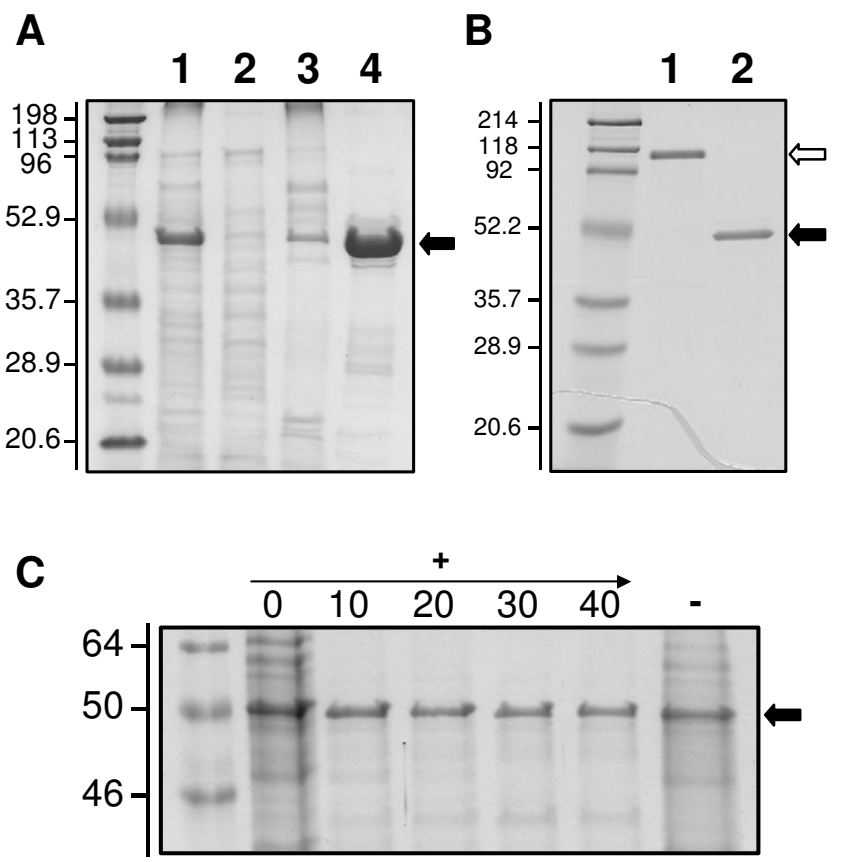

\section{Figure I}

Localization and characterization of OmpJ. A: OmpJ is the most abundant protein in the outer membrane of $G$. sulfurreducens. Subcellular fractions (cell-free extracts (lane I), soluble (lane 2), cytoplasmic membrane (lane 3) and outer membrane (lane 4) fractions; $5 \mu \mathrm{g}$ protein per lane), of $G$. sulfurreducens grown with fumarate as electron acceptor were analyzed by SDS-PAGE. The most abundant protein in the outer membrane (indicated by an arrow) was designated OmpJ. B: Heat modifiability of OmpJ. OmpJ migrated as a dimer (white arrow) in an SDS-PAGE gel in the absence of heat treatment (lane I) but migrated as a monomer (solid arrow) after heat treatment at $100^{\circ} \mathrm{C}$ for 5 minutes (lane 2). Protein, $5 \mu \mathrm{g}$ per lane. C: Effect of proteinase $\mathrm{K}$ treatment on OmpJ integrity. Outer membrane fractions were treated with different concentrations ( 0 to $\left.40 \mathrm{U} \mathrm{ml}^{-1}\right)$ of proteinase $\mathrm{K}(+)$ to analyze the surface exposure of OmpJ and their protein composition was analyzed by denaturing PAGE. A negative control without proteinase $\mathrm{K} \mathrm{(-)}$ also is shown. First lane in all panels corresponds to molecular weight standards. Numbers at left are molecular masses in kDa.

twice that of the heat-treated protein (Fig. 1B), indicative of heat modifiability $[20,21]$. In addition, in situ proteinase $\mathrm{K}$ treatment of intact cells of $\mathrm{G}$. sulfurreducens did not digest OmpJ (Fig. 1C) while OmpJ integrity was affected after proteinase $\mathrm{K}$ treatment of outer membrane fractions (data not shown). Incubation of intact cells with proteinase $\mathrm{K}$ leads to the degradation of exposed outer membrane proteins, while subsurface proteins such as porins remain protected against proteolysis. Taken together, these data greatly strengthen our assertion that (i) OmpJ is located in the outer membrane, (ii) it is tightly embedded within the membrane and (iii) it is not significantly exposed on the cell surface, as expected of a porin.

\section{Presence of ompJ in other Geobacteraceae}

Homologs of ompJ were found in the genomes of the two other members of the Geobacteraceae for which complete sequences are available,Geobacter metallireducens and Pelobacter carbinolicus (Fig. 2). A hypothetical protein in the genome of G. metallireducens (gi-48845525) had the highest identity at the amino acid level, $70.2 \%$ (out of 476 amino acids), and $80 \%$ similarity to OmpJ of G. sulfurreducens. A protein also was identified in $P$. carbinolicus (GenBank, accession number DQ004247) that shared $34 \%$ identity (out of 513 amino acids) and 51\% similarity with G. sulfurreducens OmpJ. No close OmpJ homologs were found in the NCBI database outside the Geobacteraceae family. OmpJ had $21 \%$ identity and $33.3 \%$ similarity at the amino acid level with Omp35 of S. oneidensis MR-1 (Fig. 2), a porin-like protein found to have an indirect effect in metal reduction in this organism [22]. However, while OmpJ had no similarity to other porins in the database, Omp35 was most closely similar to known bacterial porins such as PorA of Neisseria meningitidis [22]. These results suggest that $\mathrm{OmpJ}$ is a novel type of porin that is unique to the Geobactereaceae.

\section{Characterization of an OmpJ-deficient mutant}

The presence of the ompJ gene in the Geobacteraceae family but not in any other group of bacteria, suggested that OmpJ might play a key role in the physiology of these metal reducers. In order to elucidate the physiological role of G. sulfurreducens OmpJ, a deletion mutant was constructed by gene replacement with a kanamycin cassette (Fig. 3A). SDS-PAGE analyses confirmed the absence of the OmpJ protein band in outer membrane preparations of the OmpJ-deficient mutant but also showed significant differences in the protein composition of the mutant outer membrane fraction when compared to the wildtype, with some absent proteins and some new proteins present in the outer membrane fractions of the mutant (Fig. 3B)

The OmpJ-deficient mutant strain reduced fumarate nearly as well as the wild-type strain (Fig. 4A). However, it was markedly deficient in the reduction of metals such as soluble Fe (III) citrate (Fig. 4B), insoluble poorly crystalline Fe (III) oxide (Fig. 4C), as well as Mn (IV) oxides (Fig. 4D) when compared to the wild-type strain. Attempts to complement the mutation in trans yielded a strain that produced OmpJ only at levels ca. $10 \%$ of the wild-type, as visualized on denaturing gels (data not shown). Such suboptimal levels of complementation have previously been observed in previous studies on the function of other 


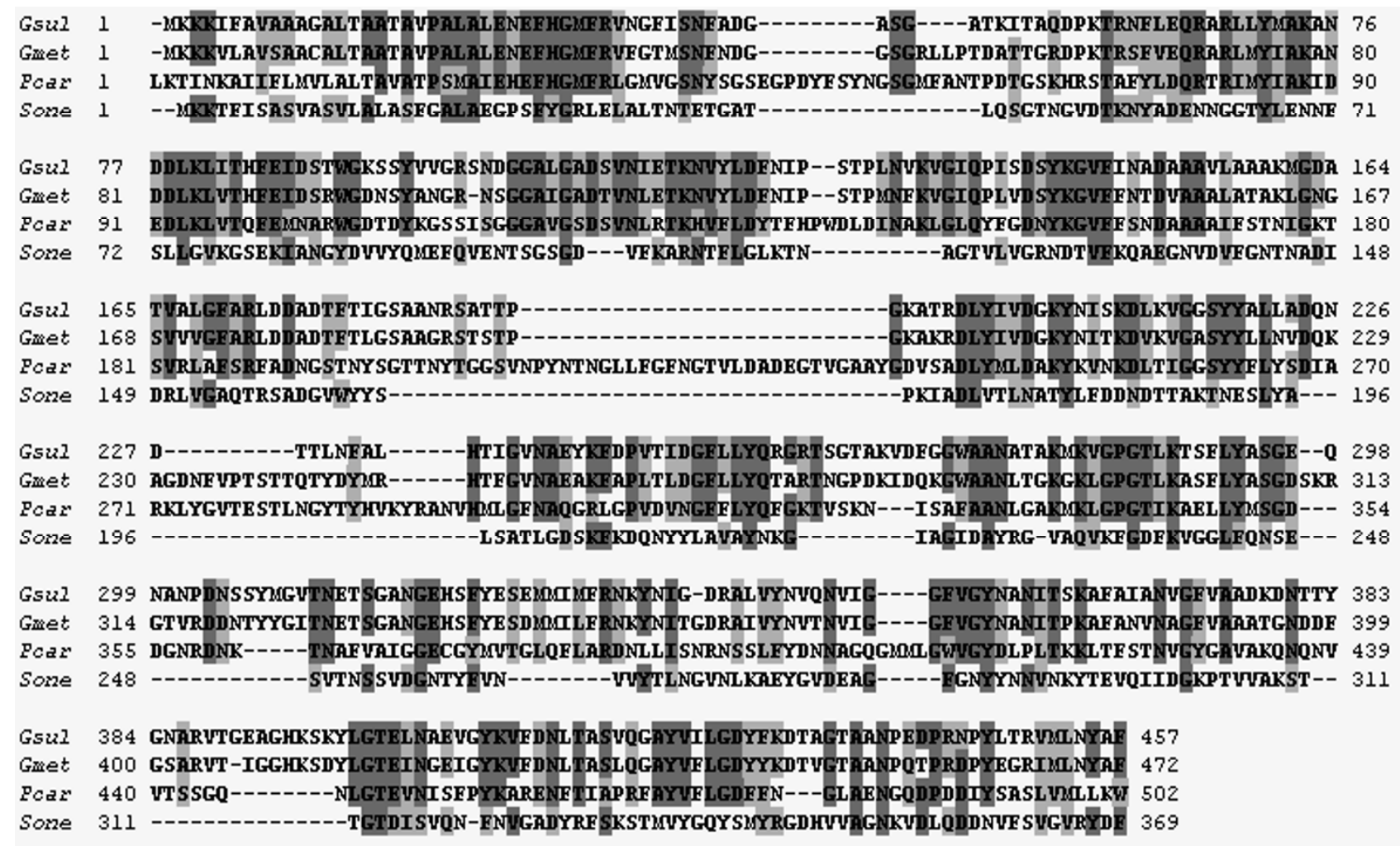

Figure 2

Amino acid sequence alignment of OmpJ, OmpJ homologs in other members of the Geobacteraceae and Omp35, a porin-like protein from S. oneidensis MR-I. Identical residues are highlighted in dark grey and similar residues in light grey. Abbreviations: Gsul; Geobacter sulfurreducens OmpJ; Gmet, G. metallireducens OmpJ homolog; Pcar, P. carbinolicus OmpJ homolog; Sone, S. oneidensis MR-I Omp35.

genes in G. sulfurreducens $[13,14]$. However, even with suboptimal levels of OmpJ, $16 \%$ of the Fe (III) citrate reduction capacity was restored (data not shown).

The loss of the capacity for Fe (III) and Mn (IV) reduction in the ompJ mutant was associated with a significant loss of $c$-type cytochromes from the cell. The $c$-type cytochrome content in cell extracts of the wild-type was $20 \pm$ $0.7 \mu \mathrm{mol}$ per $100 \mathrm{mg}$ protein whereas the mutant's $c$-type cytochrome content was $10 \pm 0.2 \mu \mathrm{mol}$ per $100 \mathrm{mg}$ protein. Heme $c$ staining of proteins separated by SDS-PAGE confirmed there was a loss of a number of both soluble and membrane-associated cytochromes in the OmpJ-deficient mutant strain (Fig. 5). There was also an apparent increase in the abundance of a $70 \mathrm{kDa} c$-type cytochrome associated with the inner membrane.
Because porins also have been shown to play a structural role in the integrity of the bacterial cell surface $[23,24]$, cells were examined with transmission electron microscopy (TEM). TEM analyses of negatively-stained cells and of thin sections of cells from fumarate-grown cultures showed that the appearance of the mutant cells was remarkably different from the wild-type cells and was consistent with an enlarged periplasm (Fig. 6).

\section{Discussion}

The results presented in this work suggest that the most abundant outer-membrane protein in G. sulfurreducens is a probable porin and, despite its apparent lack of any moieties capable of participating in electron transfer, its presence is required in order for $G$. sulfurreducens to reduce extracellular electron acceptors, such as soluble Fe(III) 
A

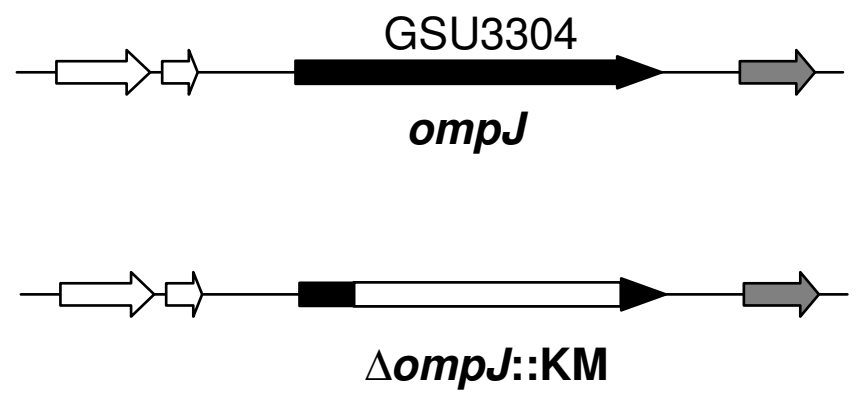

B

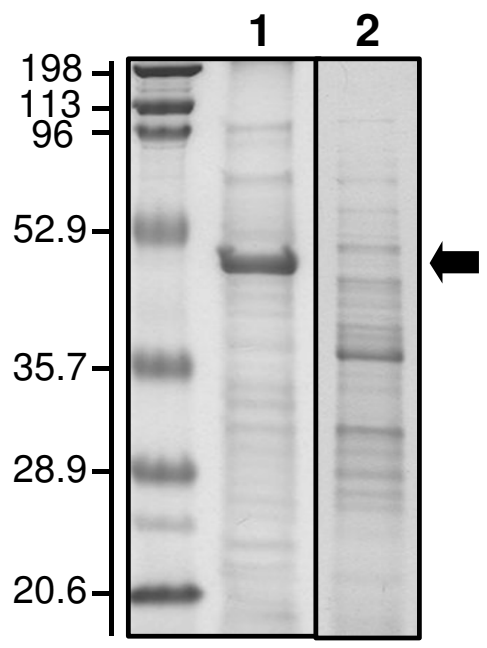

\section{Figure 3}

Generation of an OmpJ-deficient mutant of G. sulfurreducens. A: An OmpJ-deficient mutant of $G$. sulfurreducens was constructed by gene replacement with a kanamycin cassette. B: Protein composition of outer membrane fractions of the wildtype (lane I) and an OmpJ-deficient mutant (lane 2) showing the absence of the OmpJ band in the mutant strain (indicated by an arrow). First lane corresponds to molecular weight standards. Numbers at left are molecular masses in kDa.

citrate and insoluble Fe (III) and Mn (IV) oxides. These results, coupled with the recent discovery of the importance of a porin-like protein, designated Omp35, in Fe (III) reduction in Shewanella oneidensis MR-1 [22], emphasize that porins play an important role in the maintenance of the physical integrity and function of the cell surface in dissimilatory metal-reducing microorganisms.

\section{Physiological role of OmpJ}

OmpJ's annotation as a porin is consistent with the predicted beta-barrel structure of the protein [25] and with several pieces of biochemical evidence such as its location and abundance in the outer membrane (Fig. 1A) and the results of our proteinase $\mathrm{K}$ study, which suggest that it is embedded in the membrane (Fig. 1C). Also, porins often assemble in the outer membrane as multimeric structures composed of several porin monomers [24] and, as a result, many porins exhibit heat modifiability $[20,21]$. As was shown in Fig. 1B, OmpJ also showed heat modifiability.

Bacterial outer membrane porins have been studied extensively $[24,25]$ and porin-like proteins also are found in chloroplasts and mitochondria [26]. Porins represent an unusual class of membrane proteins in that they exhibit no hydrophobic stretches in their amino acid sequences and form hollow beta-barrel structures with a hydropho- bic outer surface. The barrel structure encompasses the trans-membranous pore that allows the passive diffusion of hydrophilic solutes across the (outer) membrane [25]. The enlarged periplasm observed in the OmpJ-deficient mutant, as compared to that of the wild type cells, further suggests some role in solute transport. Although OmpJ is annotated in the genome of G. sulfurreducens as a putative protein of the LamB porin superfamily, this classification does not necessarily imply a physiological role analogous to that of LamB channels. The LamB superfamily comprises channels involved in the spontaneous diffusion of specific nutrients. The LamB protein of E. coli, which also serves as the phage lambda receptor, is a prototype of this class of channels and catalyzes the influx of maltose and maltodextrins and also facilitates the influx of various carbohydrates when in low concentrations in the extracellular environment [24]. However, Geobacter species are not known to use sugars as substrates. The finding that the ompJ deletion mutant reduced fumarate at rates comparable to the wild-type suggests that the transport of the electron donor, acetate, or essential nutrients, such as ammonia, phosphate, sulfur, amino acids and trace metals, which are necessary in central metabolic reactions, was not inhibited. Morevover, the enlarged periplasmic space observed upon deletion of the ompJ gene is consistent with a channel involved in the efflux, rather than influx, of some nutrient. 

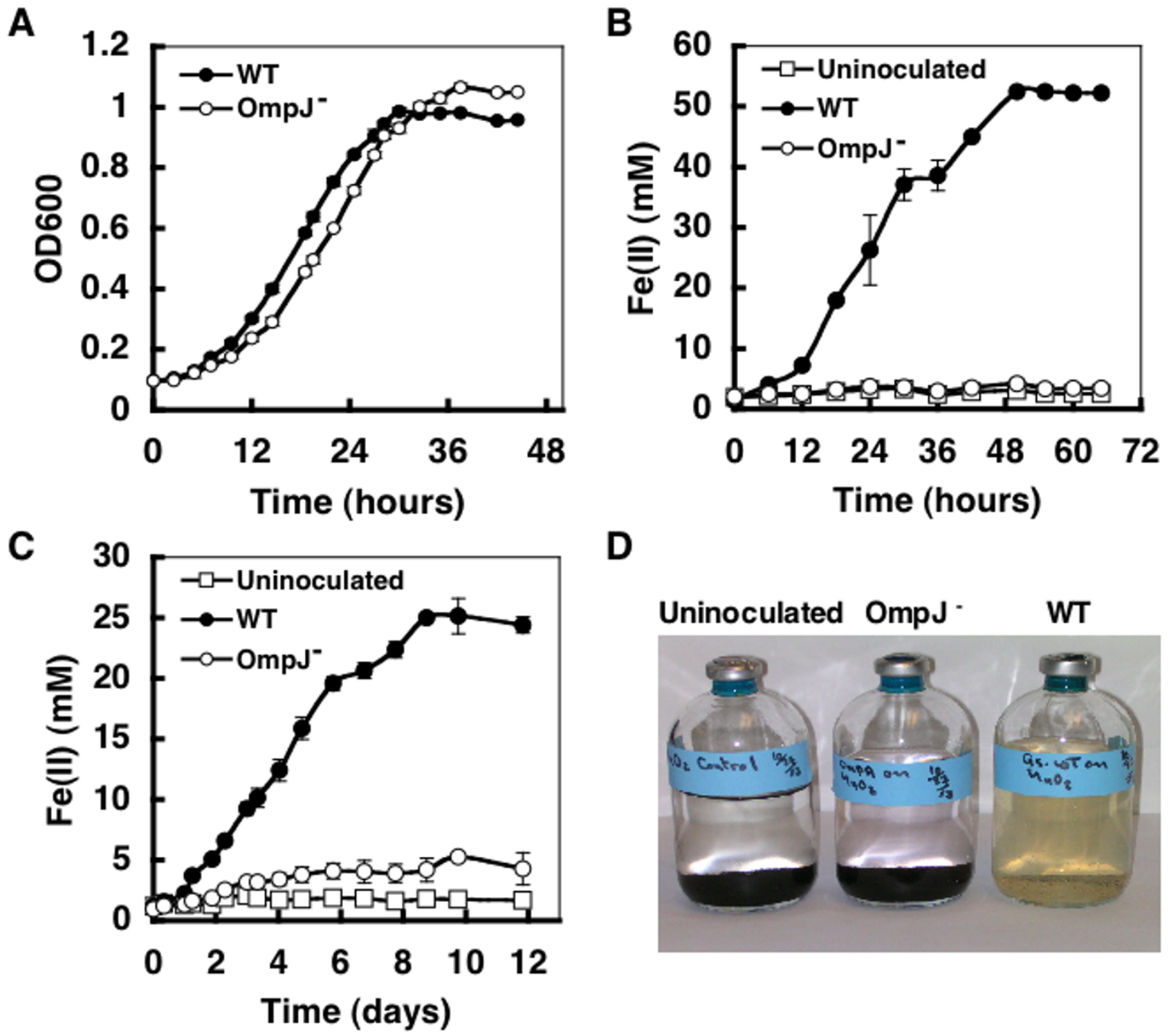

D

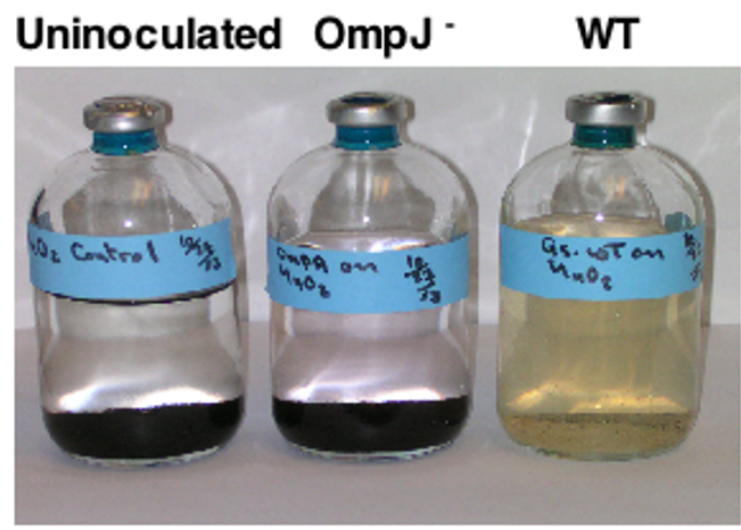

\section{Figure 4}

Physiological characterization of an OmpJ-deficient mutant. The growth of the wild-type (WT) and OmpJ-deficient mutant (OmpJ-) strains with fumarate (A), Fe(III) citrate (B), and insoluble Fe(III) (C) or Mn(VI) (D) oxides was studied. Growth on fumarate was quantified by following the optical density of the culture at $600 \mathrm{~nm}$ (OD600), while growth with soluble or insoluble $\mathrm{Fe}(\mathrm{III})$ was monitored by measuring the levels of soluble $\mathrm{Fe}$ (II) present in the medium as a result of Fe(III) reduction. Error bars are the standard deviation from the average of triplicate determinations. The reduction of $\mathrm{Mn}(\mathrm{VI})$ oxides was visually tested as the oxidized $\mathrm{Mn}(\mathrm{VI})$ oxides turn from black to a whitish precipitate upon reduction. Uninoculated controls also were included in B-D.

It is unlikely that OmpJ is involved in the final electron transfer to Fe (III) and Mn (IV) because it lacks any apparent electron transfer moieties and because it appears to be embedded within the membrane rather than exposed externally. In addition, other non-cytochrome proteins, type IV pili, have recently been shown to be involved in the final electron transfer to insoluble metals [8]. Thus, the effect of the ompJ mutation in the inhibition of Fe (III) and Mn (IV) reduction appears to be indirect, as a result of the general reduction in the production of $c$-type 

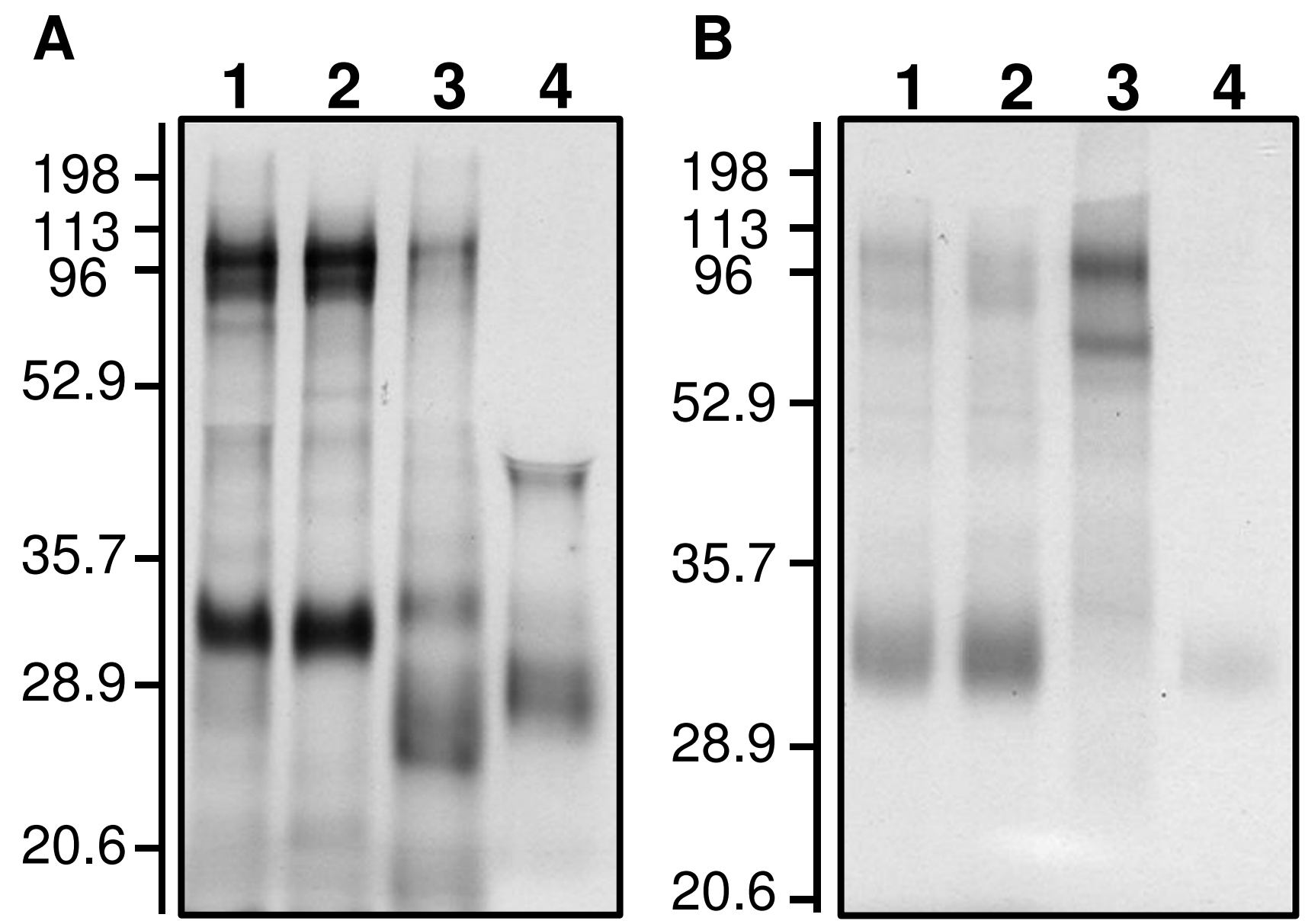

\section{Figure 5}

Heme-stained protein composition of a WT (A) and an OmpJ-deficient mutant (B). A: Distribution of hemestained proteins in subcellular fractions of $G$. sulfurreduces wild-type. Lane I, total cell free extract; lane 2, soluble fractions; lane 3, inner membrane; and lane 4, outer membrane; $10 \mu \mathrm{g}$ protein per lane. B: Distribution of heme-stained proteins in subcellular fractions of an OmpJ-deficient mutant. Lane I, total cell free extract; lane 2, soluble fractions; lane 3, inner membrane; and lane 4, outer membrane; $10 \mu \mathrm{g}$ protein per lane. Numbers at left are molecular masses in kDa.

cytochromes. Previous studies have suggested that a number of $c$-type cytochromes are required in order for $G$. sulfurreducens to effectively reduce metals and the loss of just one of these may inhibit Fe (III) reduction [13,14,27]. In some instances, outer-membrane proteins may be required for the proper localization of outer-membrane $c$ type cytochromes [28] and, if not properly localized and folded, cytochromes may be proteolytically degraded. However, a direct role for OmpJ in the proper localization of $c$-cytochromes is unlikely because OmpJ homologs are also present in Pelobacter species, which reduce Fe (III) but do not contain detectable $c$-type cytochromes [17]. Alternatively, OmpJ may be required for transport of some constituent such as iron that is required for $c$-cytochrome production. The swelling of the periplasm in fumarategrown cells suggests, however, that transport of one or more solutes out of the cell might be inhibited in the absence of OmpJ. This abnormal periplasm is likely to interfere with protein folding and localization, thus inducing the extracytoplasmic stress responses, mediated by the RpoE sigma factor and Cpx systems in E. coli [29], and triggering a proteolytic cascade that relieves the accumulation of misfolded proteins in the periplasm [30].

\section{Porins and metal reduction}

OmpJ of G. sulfurreducens is the first porin ever to be described in detail in any member of the delta-Proteobacteria [24]. Similar to Omp35, a porin-like protein from 

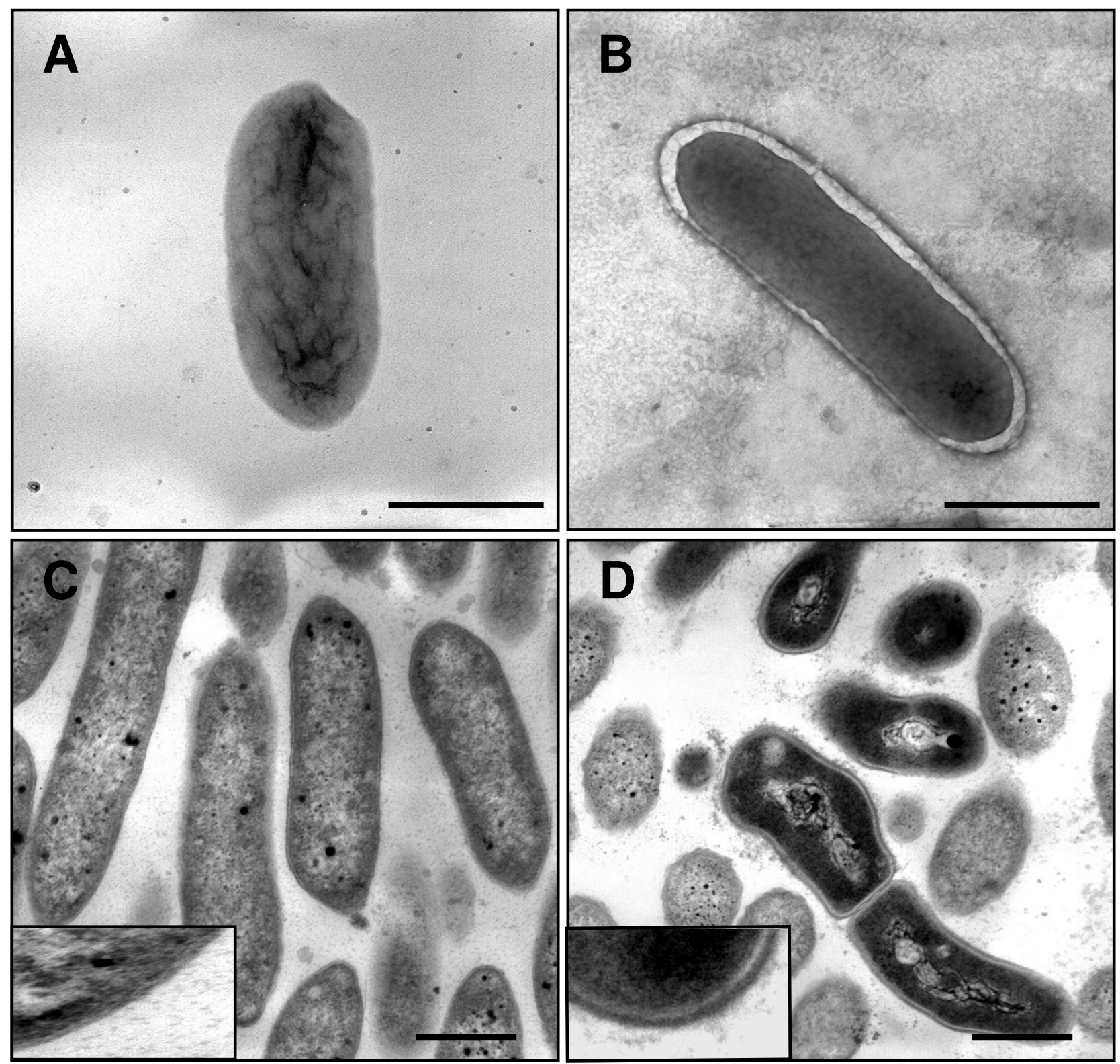

\section{Figure 6}

Microscopic analyses of an OmpJ-deficient mutant. Transmission Electron Microscopy analyses of cells of the wild-type (A and $\mathbf{C}$ ) and an OmpJ-deficient mutant (B and $\mathbf{D}$ ) showing the enlargement of the periplasmic space in the OmpJ-mutant cells when compared with the wild type. $\mathbf{A}$ and $\mathbf{B}$ show negatively stained cells while $\mathbf{C}$ and $\mathbf{D}$ show micrographs of thin sections of, respectively, cells of the wild-type and OmpJ-deficient mutant strains. Bars, I $\mu \mathrm{m}$.

Shewanella oneidensis MR-1 [22], it appears to have an indirect role in metal reduction. While an Omp35-deficient mutant in $S$. oneidensis had slower rates of reduction of fumarate and soluble or insoluble $\mathrm{Fe}(\mathrm{III})$ [22], deletion of OmpJ of G. sulfurreducens did not affect fumarate reduction but dramatically inhibited metal reduction such as 
soluble or insoluble $\mathrm{Fe}(\mathrm{III})$ and $\mathrm{Mn}$ (VI) oxides. This is not surprising inasmuch as fumarate reduction occurs intracellularly in G. sulfurreducens [31] while the S. oneidensis terminal reductase is periplasmic [32]. Interestingly, the levels and distribution of key components of electron transport in $S$. oneidensis such as quinones and cytochromes were normal in the Omp35-deficient mutant [22], whereas the OmpJ-deficient mutant of G. sulfurreducens had a substantial reduction in heme $c$ and $c$-cytochrome abundance, which may have indirectly contributed to the marked decrease of its metal reduction potential. The lack of homology and differences in function between Omp35 and OmpJ may reflect the profound differences in the mechanisms for $\mathrm{Fe}(\mathrm{III})$ reduction in Shewanella and Geobacter species [1].

Most importantly, these studies emphasize the role of non-electron transport proteins in electron transfer to a variety of electron acceptors. OmpJ of G. sulfurreducens is of special significance because, unlike Omp35, it is widespread in members of the Geobacteraceae, but no homologs are found in any other bacterial groups. This suggests that screening for ompJ-like sequences may be a good strategy for identifying Geobacteraceae sequences in libraries of environmental genomic DNA. Furthermore, ompJ provides another gene in the short, but growing, list of Geobacteraceae-specific sequences that might be used to quantify the number of Geobacteraceae in Fe (III)-reducing environments or to infer rates of activity of these organisms from quantitative mRNA analysis $[33,34]$.

\section{Conclusion}

In summary, OmpJ is an abundant outer-membrane protein in G. sulfurreducens and it is required for metal reduction in this organism. OmpJ also is required to keep the structural integrity of the periplasmic space, which is necessary for proper folding and functioning of electron transport components. Thus, the role of OmpJ in metal reduction may, in fact, be indirect. While the actual role of this apparent porin is still uncertain, further studies on interactions of OmpJ with other proteins in G. sulfurreducens may help to better elucidate its function.

\section{Methods}

\section{Bacterial strains and culture conditions}

All strains used in this work were isogenic with the wildtype G. sufurreducens strain PCA (ATCC 51573) [35], obtained from our laboratory culture collection. A deletion mutant in the ompJ gene (GSU3304) was constructed by cross-over PCR replacing the +311 to +1245 coding region with a kanamycin (KM) cassette, as previously described $[27,36]$. Briefly, the upstream region of ompJ was amplified with primers upF (5'-GCGTTGACAGACAAACTC-3') and upR (5'-GCCATCGTTCGATCTTCCG-3') and the downstream region with primers dwnF
(5'-CAAGGTGTTTGACAACCTG-3') and dwnR (5'- CAAGGTGTTTGACAACCTG-3'). The KM-resistance cassette in plasmid pBBR1MCS-2 [37] was PCR-amplified with primers kanF (5'- CGGAAGATCGAACGATGGCACCTGGGATGAATGTCAGC-3') and kanR (5'CAGGTTGTCAAACACCTTGATGGCAGGTT-

GGGCGTCGC-3'). The three PCR-amplified fragments were used as templates in a recombinant PCR reaction [38] using primers upF and dwnR to amplify a $1.951 \mathrm{~kb}$ DNA fragment. Electroporation and mutant isolation were performed as described previously [18]. The mutation was confirmed by PCR and Southern blotting [38]. The ompJ mutation was complemented in trans using plasmid pCM66-OmpJ, a pCM66 [39] derivative carrying a wild-type copy of the ompJ coding region previously amplified using primers OmpJ01 (5'-GGAAGCTTCCATGCTGTTTTATCATACCC-3') and OmpJ02 (5'-GGGAATTCGGTGATGCAATTAGAATG-3').

Cells were routinely cultured under strict anaerobic conditions in freshwater (FW) medium, as previously described [40], with $20 \mathrm{mM}$ sodium acetate as the electron donor and either $55 \mathrm{mM} \mathrm{Fe}$ (III)-citrate, $40 \mathrm{mM}$ fumarate, poorly crystalline Fe (III) oxide (100 mmol/l), or $\mathrm{MnO}_{2}(3 \mathrm{~mol} /$ l) as the electron acceptor.

\section{Preparation of outer membrane proteins and PAGE analyses}

Cells for protein analyses were grown in 1-liter bottles or, for mass cultivation, in 10-liter carboys to late-exponential phase, harvested by centrifugation $(12,000 \mathrm{xg}$ for 10 min at $4^{\circ} \mathrm{C}$ ), and washed with $10 \mathrm{mM}$ Tris- $\mathrm{HCl}(\mathrm{pH} \mathrm{8.0})$ containing $1 \mathrm{mM}$ EDTA and $10 \mu \mathrm{M}$ phenol methyl-sulfonyl fluoride (PMSF) to inhibit proteolytic activities. Cell samples were routinely stored at $-20^{\circ} \mathrm{C}$. Before use, cell samples were suspended in $10 \mathrm{mM}$ Tris- $\mathrm{HCl}$ buffer $(\mathrm{pH}$ 7.5) at $4{ }^{\circ} \mathrm{C}$, and subjected to three passes through a French pressure cell at 10,000 psi to lyze the cells (cell-free extract). Cell debris and intact cells were separated by centrifugation $(12,000 \mathrm{~g}$ for $20 \mathrm{~min})$ and the cell-free extract was further centrifuged $(100,000 \times \mathrm{g}$ for $1 \mathrm{~h})$ to separate the soluble fraction (SF) from the crude membrane pellet. The pellet was resuspended in $10 \mathrm{mM}$ Tris- $\mathrm{HCl}$ buffer $(\mathrm{pH}$ 7.5) and lauroyl sarcosine-sodium salt was added to a final concentration of $1 \%(\mathrm{w} / \mathrm{v})$ in order to selectively solubilize cytoplasmic membrane proteins [41]. The mixture was stirred at room temperature for 1 to $2 \mathrm{~h}$ and then centrifuged at $100,000 \times \mathrm{g}$ for $1 \mathrm{~h}$. The supernatant, containing the solubilized cytoplasmic membrane protein fraction $(\mathrm{CM})$, was collected and stored at $-20^{\circ} \mathrm{C}$. The pellet, which contains the outer membrane fraction (OM), was washed three times in $10 \mathrm{mM}$ Tris- $\mathrm{HCl}$ buffer $(\mathrm{pH}$ 7.5) containing $10 \mathrm{mM} \mathrm{MgCl}, 2 \% \mathrm{NaCl}$, and $10 \mu \mathrm{M}$ PMSF. 
Protein profiles in the various fractions were analyzed by SDS-Polacrylamide Gel Electrophoresis (SDS-PAGE, 15 $\%$ ) in a Mini-Protean 3 Cell (Bio-Rad). Prior to electrophoresis, OM protein samples were mixed (1:2) in Laemmli sample buffer (Bio-Rad), containing $\beta$ mecaptoethanol and boiled for $10 \mathrm{~min}$ at $100^{\circ} \mathrm{C}$. Protein separation prior to staining for heme $c$-containing proteins with $N, N, N^{\prime}, N^{\prime}$-tetramethylbenzidine $[42,43]$ was performed in the same manner except that $\beta$-mecaptomethanol was omitted from the sample buffer and boiling time was reduced to $5 \mathrm{~min}$. The most abundant protein band from the OM fraction was excised from the gel, digested with trypsin in the presence of $0.01 \% \mathrm{n}$ octylglucopyranoside, and analyzed with matrix-assisted laser desorption ionization- time of flight (MADI-TOF) mass spectrophotometry (Kratos Axima CFR; Kratos Analytical, Manchester, England) [44].

\section{In situ proteinase $K$ treatment}

Surface exposure of the OmpJ protein was assayed with proteinase $\mathrm{K}$ as a modification of a previously described protocol [45]. Cells were grown to mid-exponential phase in FW medium containing $20 \mathrm{mM}$ acetate and $40 \mathrm{mM}$ fumarate and harvested by centrifugation $(20 \mathrm{~min}$ at $\left.13,000 \mathrm{rpm}, 4^{\circ} \mathrm{C}\right)$. After two washes in a $10 \mathrm{mM}$ Tris- $\mathrm{HCl}$ buffer ( $\mathrm{pH} 8.0$ ) containing $10 \mathrm{mM} \mathrm{MgCl}$ and $2 \% \mathrm{NaCl}$, cells were suspended in the same buffer to a final concentration of $63 \mathrm{mg}$ of wet cells per ml. Examination of the bacterial suspension by phase-contrast microscopy did not indicate detectable bacterial lysis. Proteinase $\mathrm{K}$ was gradually added to the cell suspension at concentrations ranging from 0 to $40 \mathrm{U} \mathrm{ml}^{-1}$. A negative control with added buffer, instead of proteinase $\mathrm{K}$, and another using outer membrane fractions, instead of intact cells, also were included. Samples were stirred at room temperature for $15 \mathrm{~min}$ with various concentrations ( 0 to $40 \mathrm{U} \mathrm{ml}^{-1}$ ) of proteinase K before a protease cocktail inhibitor (Roche) was added to stop the proteolytic reaction. The cells were pelleted by centrifugation at $14,000 \mathrm{rpm}$ for $5 \mathrm{~min}$, washed twice in 10X volumes of the same buffer containing the protease inhibitor cocktail, and resuspended in the same buffer with the protease inhibitor cocktail. Aliquots of the cell suspensions $\left(10 \mathrm{mg}\right.$ protein $\left.\mathrm{ml}^{-1}\right)$ were diluted 1:2 in SDS-sample buffer and boiled for $10 \mathrm{~min}$ prior to separation by SDS-PAGE, as described above.

\section{C-type cytochromes analyses}

Cells of the wild-type and mutant strains were grown to mid-exponential phase with fumarate as the electron acceptor and harvested. Cell-free extract, soluble, CM, and OM protein fractions were prepared as described above. The total heme $c$ content of each fraction ( $100 \mu \mathrm{g}$ protein) was determined by the pyridine ferrohemochrome method [46]. In addition, every fraction (10 $\mu \mathrm{g}$ protein) was separated by SDS- PAGE (15\%) at $125 \mathrm{~V}$ for 2-3 hrs and the gel was stained for heme $c$-containing proteins as previously described $[42,43]$.

\section{Transmission Electron Microscopy (TEM)}

Cells for TEM analyses were grown to mid-exponential phase in FW medium with fumarate, fixed on to the surface of carbon-coated copper grids with glutaraldehyde and negatively stained with $2 \%$ uranyl acetate. For thin sections, cells were fixed in glutaraldehyde and stained with osmium tetraoxide following standard microscopy procedures. Samples were analyzed in a JEOL $100 S$ transmission electron microscope operated at $60-80 \mathrm{~V}$.

\section{Analytical methods}

$\mathrm{Fe}(\mathrm{II})$ production was monitored by the ferrozine assay at $12 \mathrm{hr}$ intervals [40]. Protein concentration was determined by the bicinchoninic acid method with Bovine Serum Albumin (BSA) as a standard [47].

\section{Sequence analyses}

The PSORT algorithm http://us.expasy.org was used to predict the cell localization of the OmpJ protein. The genome sequences of Geobacter metallireducens and Pelobacter carbinolicus can be found at http://www.jgi.doe.gov. The genome sequence of G. sulfurreducens can be found at http://www.tigr.org.

\section{Authors' contributions}

EA conducted most of the experiments and analyzed some of the data. GR conducted the microscopy experiments and some phenotypic characterization, analyzed and organized the data, and drafted most of the manuscript. MS conducted the analyses of the OmpJ porin amino acid sequence. DRL conceived the overall project, provided experimental guidance, and drafted portions of the manuscript. All authors read and approved the final manuscript.

\section{Acknowledgements}

The authors would like to thank Maddalena Coppi and Ching Leang for their advice during the development of different parts of this work and John Leszyk (Proteomic Mass Spectrometry Lab, UMass Medical School) for assistance with MALDI-TOF mass spectrometry analyses. Also thanks to Laurie Didonato, Richard Glaven, Richard Ding, and Evgenya Shelobolina for technical assistance and helpful discussions. MS acknowledges support from the Office of Science (BER), U. S. Department of Energy NABIR program under Contract W-3I-109-Eng-38. This research was supported by the Office of Science (BER), U. S. Department of Energy, and Cooperative Agreement No. DE-FC02-02ER634, and by the Office of Science (BER), U. S. Department of Energy, Grant No. DE-FG02-02ER63423 to DRL.

\section{References}

I. Lovley DR, Holmes DE, Nevin K: Dissimilatory Fe(III) and Mn(IV) reduction. Adv Microb Physiol 2004, 49:219-286.

2. Lovley DR: Cleaning up with genomics: applying molecular biology to bioremediation. Nat Rev Microbiol 2003, I:35-44.

3. Finneran KT, Housewright ME, Lovley DR: Multiple influences of nitrate on uranium solubility during bioremediation of ura- 
nium-contaminated subsurface sediments. Environ Microbiol 2002, 4:510-516.

4. Anderson RT, Vrionis HA, Ortiz-Bernad I, Resch CT, Long PE, Dayvault R, Karp K, Marutzky S, Metzler DR, Peacock A, White DC, Lowe M, Lovley DR: Stimulating the in situ activity of Geobacter species to remove uranium from the groundwater of a uranium-contaminated aquifer. Appl Environ Microbiol 2003, 69:5884-5891.

5. Ortiz-Bernad I, Anderson RT, Vrionis HA, Lovley DR: Vanadium respiration by Geobacter metallireducens: novel strategy for In situ removal of vanadium from groundwater. Appl Environ Microbiol 2004, 70:309I-3095.

6. Nevin KP, Lovley DR: Lack of production of electron-shuttling compounds or solubilization of $\mathrm{Fe}$ (III) during reduction of insoluble Fe(III) oxide by Geobacter metallireducens. Appl Environ Microbiol 2000, 66:2248-225I.

7. Childers SE, Ciufo S, Lovley DR: Geobacter metallireducens accesses insoluble Fe(III) oxide by chemotaxis. Nature 2002, 416:767-769.

8. Reguera G, McCarthy KD, Mehta T, Nicoll JS, Tuominen MT, Lovley DR: Extracellular electron transfer via microbial nanowires. Nature 2005, 435: 1098-1101.

9. Nevin KP, Lovley DR: Mechanisms for Fe(III) oxide reduction in sedimentary environments. Geomicrobiol J 2002, 19:14I-159.

10. Newman DK, Kolter R: A role for excreted quinones in extracellular electron transfer. Nature 2000, 405:94-97.

II. Nevin KP, Lovley DR: Mechanisms for accessing insoluble $\mathrm{Fe}$ (III) oxide during dissimilatory $\mathrm{Fe}(\mathrm{III})$ reduction by Geothrix fermentans. Appl Environ Microbiol 2002, 68:2294-2299.

12. Magnuson TS, Hodges-Myerson AL, Lovley DR: Characterization of a membrane-bound NADH-dependent $\mathrm{Fe}(3+)$ reductase from the dissimilatory $\mathrm{Fe}(3+)$-reducing bacterium Geobacter sulfurreducens. FEMS Microbiol Lett 2000, 185:205-2II.

13. Leang C, Coppi MV, Lovley DR: OmcB, a c-type polyheme cytochrome, involved in $\mathrm{Fe}$ (III) reduction in Geobacter sulfurreducens. J Bacteriol 2003, 185:2096-2103.

14. Butler JE, Kaufmann F, Coppi MV, Nunez C, Lovley DR: MacA, a diheme c-type cytochrome involved in $\mathrm{Fe}$ (III) reduction by Geobacter sulfurreducens. J Bacteriol 2004, I 86:4042-4045.

15. Methé BA, Nelson KE, Eisen JA, Paulsen IT, Nelson W, Heidelberg JF, Wu D, Wu M, Ward N, Beanan MJ, Dodson RJ, Madupu R, Brinkac LM, Daugherty SC, DeBoy RT, Durkin AS, Gwinn M, Kolonay JF, Sullivan SA, Haft DH, Selengut J, Davidsen TM, Zafar N, White O, Tran B, Romero C, Forberger HA, Weidman J, Khouri H, Feldblyum TV, Utterback TR, Van Aken SE, Lovley DR, Fraser CM: Genome of Geobacter sulfurreducens: metal reduction in subsurface environments. Science 2003, 302:1967-1969.

16. Holmes DE, Nevin KP, Lovley DR: Comparison of I6S rRNA nifD, recA, gyrB, rpoB and fusA genes within the family Geobacteraceae fam. nov. Int J Syst Evol Microbiol 2004, 54:159|-1599.

17. Lovley DR, Phillips EJP, Lonergan DJ, Widman PK: Fe(III) and SO reduction by Pelobacter carbinolicus. Appl Environ Microbiol 1995, 6I:2132-2138.

18. Coppi MV, Leang C, Sandler SJ, Lovley DR: Development of a genetic system for Geobacter sulfurreducens. Appl Environ Microbiol 2001, 67:3180-3187.

19. Kelley LA, MacCallum RM, Sternberg MJ: Enhanced genome annotation using structural profiles in the program 3D-PSSM. Mol Biol 2000, 299:499-520.

20. Nikaido H, Nakae T: The outer membrane of Gram-negative bacteria. Adv Microb Physiol 1979, 20:163-250.

21. Wexler HM: Pore-forming molecules in gram-negative anaerobic bacteria. Clin Infect Dis 1997, 25 Suppl 2:S284-6.

22. Maier TM, Myers CR: The outer membrane protein Omp35 affects the reduction of $\mathrm{Fe}(\mathrm{III})$, nitrate, and fumarate by Shewanella oneidensis MR-I. BMC Microbiol 2004, 4:23.

23. Koebnik R, Locher KP, Van Gelder P. Structure and function of bacterial outer membrane proteins: barrels in a nutshell. Mol Microbiol 2000, 37:239-253.

24. Nikaido $\mathrm{H}$ : Molecular basis of bacterial outer membrane permeability revisited. Microbiol Mol Biol Rev 2003, 67:593-656.

25. Schulz GE: The structure of bacterial outer membrane proteins. Biochim Biophys Acta 2002, I565:308-3 I7.

26. Benz R: Permeation of hydrophilic solutes through mitochondrial outer membranes: review on mitochondrial porins. Biochim Biophys Acta 1994, I $197: 167-196$.
27. Lloyd JR, Leang C, Hodges-Myerson AL, Coppi MV, Ciufo S, Methe B, Sandler SJ, Lovley DR: Biochemical and genetic characterization of PpcA, a periplasmic c-type cytochrome in Geobacter sulfurreducens. Biochem / 2003, 369:153-161.

28. Myers CR, Myers JM: MtrB is required for proper incorporation of the cytochromes OmcA and OmcB into the outer membrane of Shewanella putrefaciens MR-I. Appl Environ Microbiol 2002, 68:5585-5594.

29. Duguay AR, Silhavy TJ: Quality control in the bacterial periplasm. Biochim Biophys Acta 2004, 1694:121-134.

30. Wilken C, Kitzing K, Kurzbauer R, Ehrmann M, Clausen T: Crystal structure of the DegS stress sensor: How a PDZ domain recognizes misfolded protein and activates a protease. Cell 2004, I 1 7:483-494

31. Butler JE, Glaven RH, Esteve-Nunez A, Nunez C, Shelobolina ES, Bond DR, Lovley DR: A single bifunctional enzyme for fumarate reduction and succinate oxidation in Geobacter sulfurreducens and Geobacter metallireducens.

32. Myers CR, Myers JM: Fumarate reductase is a soluble enzyme in anaerobically grown Shewanella putrefaciens MR-I. FEMS Microbiol Lett 1992, 98: 13-20.

33. Chin KJ, Nunez A, Leang C, Lovley DR: Direct correlation between rates of anaerobic respiration and levels of mRNA for key respiratory genes in Geobacter sulfurreducens. Appl Environ Microbiol 2004, 70:5।83-5।89.

34. Holmes DE, Nevin KP, Lovley DR: In situ expression of nifD in Geobacteraceae in subsurface sediments. Appl Environ Microbiol 2004, 70:725I-7259.

35. Caccavo FJ, Lonergan DJ, Lovley DR, Davis M, Stolz JF, Mclnerney MJ: Geobacter sulfurreducens sp. nov., a hydrogen- and acetateoxidizing dissimilatory metal-reducing microorganism. Appl Environ Microbiol 1994, 60:3752-3759.

36. Murphy KC, Campellone KG, Poteete AR: PCR-mediated gene replacement in Escherichia coli. Gene 2000, 246:32I-330.

37. Kovach ME, Elzer PH, Hill DS, Robertson GT, Farris MA, Roop RM, Peterson KM: Four new derivatives of the broad-host-range cloning vector pBBRIMCS, carrying different antibioticresistance cassettes. Gene 1995, 166:175-176.

38. Sambrook JE, Fritsch F, T. M: Molecular cloning: a laboratory manual. 2nd edition. New York, Cold Spring Harbor Laboratory Press; 1989.

39. Marx CJ, Lidstrom ME: Development of improved versatile broad-host-range vectors for use in methylotrophs and other Gram-negative bacteria. Microbiology 200I, 147:2065-2075.

40. Lovley DR, Philips E): Organic matter mineralization with the reduction of ferric iron in anaerobic sediments. Appl Environ Microbiol 1986, 51:683-689.

4I. Nikaido $\mathrm{H}$ : Isolation of outer membranes. Methods Enzymol 1994, 235:225-234

42. Thomas PE, Ryan D, Levin W: An improved staining procedure for the detection of the peroxidase activity of cytochrome $P$. 450 on sodium dodecyl sulfate polyacrylamide gels. Anal Biochem 1976, 75:168-176.

43. Francis RTJ, Becker RR: Specific indication of hemoproteins in polyacrylamide gels using a double-staining process. Anal Biochem 1984, 136:509-5|4.

44. Clauser KR, Baker P, Burlingame AL: Role of accurate mass measurement $(+/-10 \mathrm{ppm})$ in protein identification strategies employing MS or MS/MS and database searching. Anal Chem I999, 7 I:287| I-2882.

45. El-Hage N, Babb K, Carroll JA, Lindstrom N, Fisher ER, Miller JC, Glimore RD, Lamine JM, Stevenson B: Surface exposure and protease insensitivity of Borrelia burgdorferi Erp (OspEfrelated) lipoproteins. Microbiology 200 I, I 47.:82I-830

46. Berry EA, Trumpower BL: Simultaneous determination of hemes $a, b$, and $c$ from pyridine hemochrome spectra. Anal Biochem 1987, 161:1-15.

47. Smith PK, Krohn RI, Hermanson GT, Mallia AK, Gartner FH, Provenzano MD, Fujimoto EK, Goeke NM, Olson BJ, C. KD: Measurement of protein using bicinchoninic acid. Anal Biochem 1985, I50:76-85. 